\title{
Assessment and Potential Survey of Lands in Khuzestan Province Using the Buckley Geometric Mean Model and Geographic Information System (GIS)
}

\author{
Mohammad Ali Firoozi ${ }^{*}$, Majid Goodarzi' ${ }^{1}$, Rahman Shirali ${ }^{2}$ \\ ${ }^{1}$ Department of Geography and Urban Planning, Faculty of Earth Sciences and GIS, Shahid Chamran University of Ahvaz, \\ Ahvaz, Iran \\ ${ }^{2}$ Geography and Rural Planning, Shahid Chamran University of Ahvaz, Ahvaz, Iran \\ Email: ${ }^{\star}$ M.Alifiroozi@scu.ac.ir
}

How to cite this paper: Firoozi, M.A., Goodarzi, M. and Shirali, R. (2017) Assessment and Potential Survey of Lands in Khuzestan Province Using the Buckley Geometric Mean Model and Geographic Information System (GIS). Open Journal of Geology, 7, 234-241.

https://doi.org/10.4236/ojg.2017.73016

Received: February 8, 2017

Accepted: March 18, 2017

Published: March 21, 2017

Copyright $\odot 2017$ by authors and Scientific Research Publishing Inc. This work is licensed under the Creative Commons Attribution International License (CC BY 4.0).

http://creativecommons.org/licenses/by/4.0/

\begin{abstract}
Today environmental assessment is considered and used as the basis and foundation of any kind of human activity. This is the science which gives human the consciousness about abilities and disabilities of his surroundings. This study tried to assess and provide the potential survey of lands in Khuzestan province for agricultural activities by taking into account the climatic elements and displaying different elements in different seasons. To achieve this goal, first produced data were analyzed in GIS software and then the data was tested by professors and experts of department of soil science and was weighted using the Buckley geometric mean model. Finally, the obtained weights were applied in the software and the obtained results are as follow: except some east parts of Khuzestan province which have proper climate for agricultural activities, other regions are not in good conditions and it is necessary to use cultivation with low water requirements and high resistance to heat and sunlight in these areas.
\end{abstract}

\section{Keywords}

Land Assessment, Climatic Parameters, Khuzestan Province, GIS, Buckley

Geometric Mean

\section{Introduction}

Shaping and arranging of the local-spatial areas have been continuously discussed in different scales and concepts, in fact, since the beginning of human life and the use of natural resources (especially water and land) [1]. Population growth and ris- 
ing living standards increase the demand for food. This has caused that human mind focuses on the advantage of the land and increase of crops and horticultural products [2]. Due to the land limitation in agricultural production, use of land should be such that not only maximize its performance [3], but also to protect it in order to provide living conditions for human lives and posterity and to prevent land degradation and erosion, decline and destruction of this vital resource [4]. Land assessment as a part of the human society assessment [5] evaluates the production potential of land in different uses (forest, meadows, plains, etc.) (Ojeda-Trejo) and shows the main use of land for a specific purpose (Willey $\mathrm{H})$. The purpose of the assessment is to determine the ability and talent of lands for specific uses, for example: agriculture, landscaping, engineering uses (construction, landfill, mines, road construction, etc.), environmental protection and catchment [6]. In fact, using land assessment, limitations and inherent potential of lands to support specific uses in the long term is identified and reduces social, economic and environmental costs [7]. Soil degradation and decline in soil fertility, contamination of soil, surface water and groundwater, saline and sonic soils in large areas of the world are just a few of the irreparable damages which are the results of unreasonable methods and changes in natural resources by man. Therefore, recognition of land production capacity and assigning them to the best and most profitable type of user is important. Planning for optimum use of lands leads to the maximum productivity of lands and natural resources will be preserved for posterity [8].

Two important aspects of land are examined in assessment: physical aspects such as soil, ups and downs and climate, and socio-economic aspects, including the size of land plots, management level, workforce, market access and so on. The physical characteristics of land are almost constant, while socio-economic factors are highly variable [9].

The main purpose of this study is to determine the capabilities and potential of the lands in Khuzestan province in terms of climatic elements; because what is important in terms of environmental assessment is the physical power and value of the land. Physical power is a power that cannot be changed and even the socio-economic aspect is dependent to the physical aspect of the land. The other purpose of this study is to determine the capability of the lands in different seasons, because the amount and extent of climatic elements are uneven in different seasons and as a result, the land will also have an uneven power and potential. Therefore, we have to evaluate the lands in terms of climatic elements in different seasons.

\section{Research Methodology}

This study is an applied study with a descriptive-analytical approach and library studies are used. In this study experts have been used for weighting the data layers using a questionnaire. In the first phase suitable criteria in the assessment of lands were identified and because of tremendous influence of climatic elements as physical aspect in determining land potential, these criteria are investigated. 
In the second phase the criteria are weighted and then this weighting is reformed and revised in the next phase and it has continued to reach a final consensus. In the end, experts' opinions are applied in multi-criteria decision-making models and using final weights incorporation in the geographical information system, fertile lands will be identified. Climatic indices needed to address this issue include: precipitation, temperature, solar radiation, relative humidity, wind speed, wind speed measured height, longitude and latitude [9].

\subsection{Data Analysis}

\subsubsection{Geographical Information System}

Geographic information system (GIS) is a designed information system for the storage and processing [10] of the data that their reference is a specific spatial location or a special geographical coordinates [11]. One of the methods of data analysis in GIS is spatial data analysis method; ((In management of spatial analysis, GIS elects information needed in the studied areas which are first positioning with GPS devices [12] and then puts them together and analyzes them [13]. The basis for the classification of spatial analysis in assessment of intended indicators is the true and accurate values that belong to the indicators [14].

\subsubsection{Buckley Geometric Mean Model}

Buckley geometric mean model is one of the development models in state analytic hierarchy process to make it fuzzy that trapezoidal fuzzy numbers are used for the use of respondents' opinions [15].

In this way, fuzzy numbers are shown as $\tilde{t}_{i j}=\left(a_{i j}, b_{i j}, c_{i j}, d_{i j}\right)$ and in geometric space, they are shown as follow (Figure 1):

In this way to facilitate the decision-making, at first the hierarchical tree is established for criteria and sub-criteria and in the next phase fuzzy judgment matrix is formed for respondents. Fuzzy judgment matrix is prepared and implemented in the following manner:

$$
\left\{\begin{array}{c}
(1,1,1,1)(a 12, b 12, c 12, d 12) \cdots(a 1 n, b 1 n, c 1 n, d 1 n) \\
\cdot \\
(a 21, b 21, c 21, d 21)(1,1,1,1) \cdots(a 2 n, b 2 n, c 2 n, d 2 n) \\
\cdot \\
\cdot \\
\cdot \\
(a n 1, b n 1, c n 1, d n 1)(a n 2, b n 2, c n 2, d n 2) \cdots(1,1,1,1)
\end{array}\right.
$$

Third phase: rows geometric mean is calculated using the following formula:

$$
\tilde{z}_{i}=\left(\prod_{j=1}^{n} \tilde{t}_{i j}\right)^{\frac{1}{n}}
$$

Forth phase: using the following formula obtained geometric mean of the rows are normalized:

$$
\tilde{r}_{i j}=\tilde{w}_{i}=\frac{\tilde{z}_{i}}{\sum_{i=1}^{n} \tilde{z}_{i}}
$$

To normalize the data at this stage, at first it is necessary that geometric mean 
of rows to be gathered together:

$$
\sum_{i=1}^{n} \tilde{z}_{i}=\tilde{z}_{1}+\tilde{z}_{2}+\tilde{z}_{3}+\cdots+\tilde{z}_{\mathbf{n}}
$$

It should be noted that if the normalized weights are for options comparison (secondary variables), they will be $\tilde{r}_{i j}$ (option $i$ weight than criterion $j$ ) and if they are associated with the main criteria or variables, they will be $\tilde{w}_{i}$.

Fifth phase: combination of options weight (than criteria) and criteria determines the final weight [16]:

$$
\tilde{U}_{i}=\sum_{j=1}^{n} \tilde{w}_{i} \tilde{r}_{i j}
$$

\section{Data Analysis}

Environmental assessment is considered as one of the most important and critical tools for shaping and arranging the local-spatial areas which can lead us into important targets to send society towards sustainable development. The main purpose of the environmental assessment can be the classification of lands in terms of use and more adjustment to the environment [17], because use and human density increases in one area can undermine the entire environment and lead to increased environmental degradation. Understanding the physical and socio-economic aspects gives the power to managers and policy makers of the society to have the best and most use of the environment by spending the least amount of cost. The most important point is that understanding this power helps them to minimize the amount of damage into the land and its power. Among the aspects of the environmental assessment, the physical aspect has particular importance, for example climatic elements are one of the parts that cannot be controlled and executives and policy makers must be affected by these elements to plan for the use of the environment. What is observed is that the issue of climatic conditions in different seasons and months of the year was less significant. This study takes into account climatic indices over the seasons and months of the year to assess the Khuzestan lands for agricultural purposes. Then, according to the limited space of this article, from each seasons just one month is discussed.

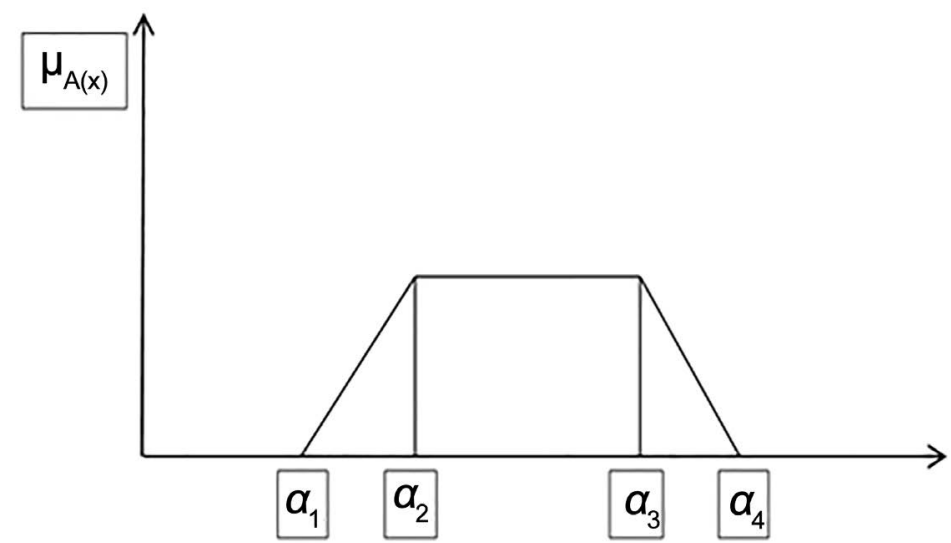

Figure 1. Trapezoidal fuzzy numbers. 


\subsection{Spring}

As it is seen in the map, in spring the best lands in terms of climatic elements are in the eastern part of the province and this value is declining from the east to the southwest of the province [18] (Figure 2).

\subsection{Summer}

Climatic conditions in August, representing the summer, is so that the most valuable lands are in the east part of the province and the least valuable lands are in all zones of the south, west and northwest. Only the southeast corner of the province is medium in terms of climatic power [18] (Figure 3).

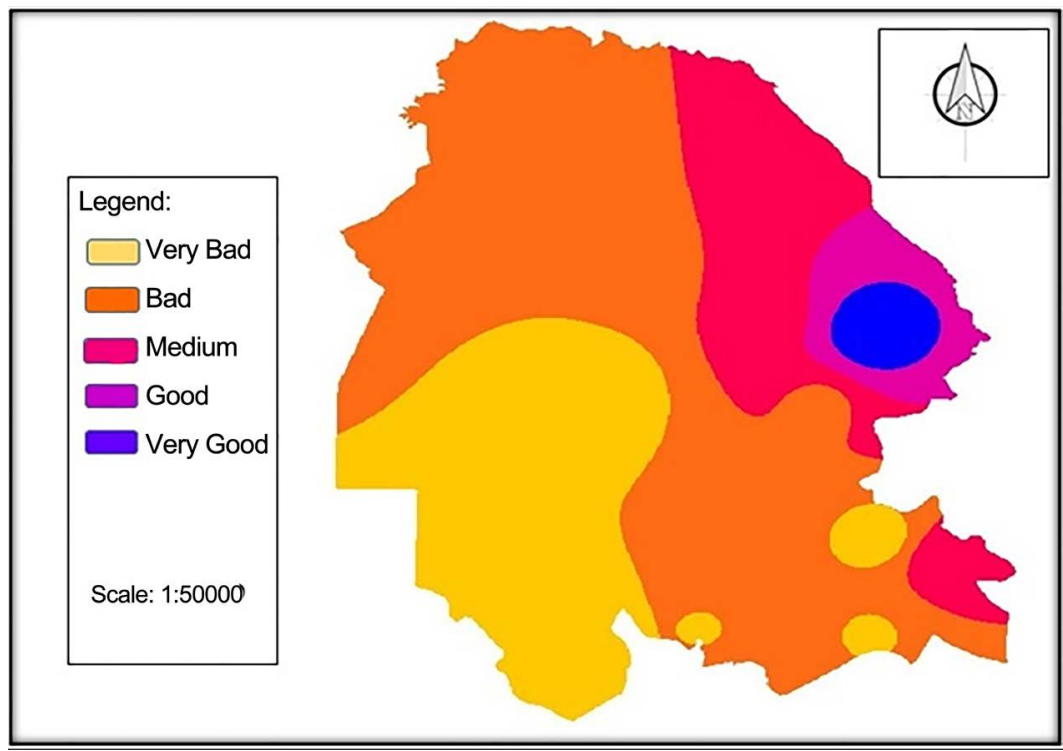

Figure 2. The status of land assessment in May, spring.

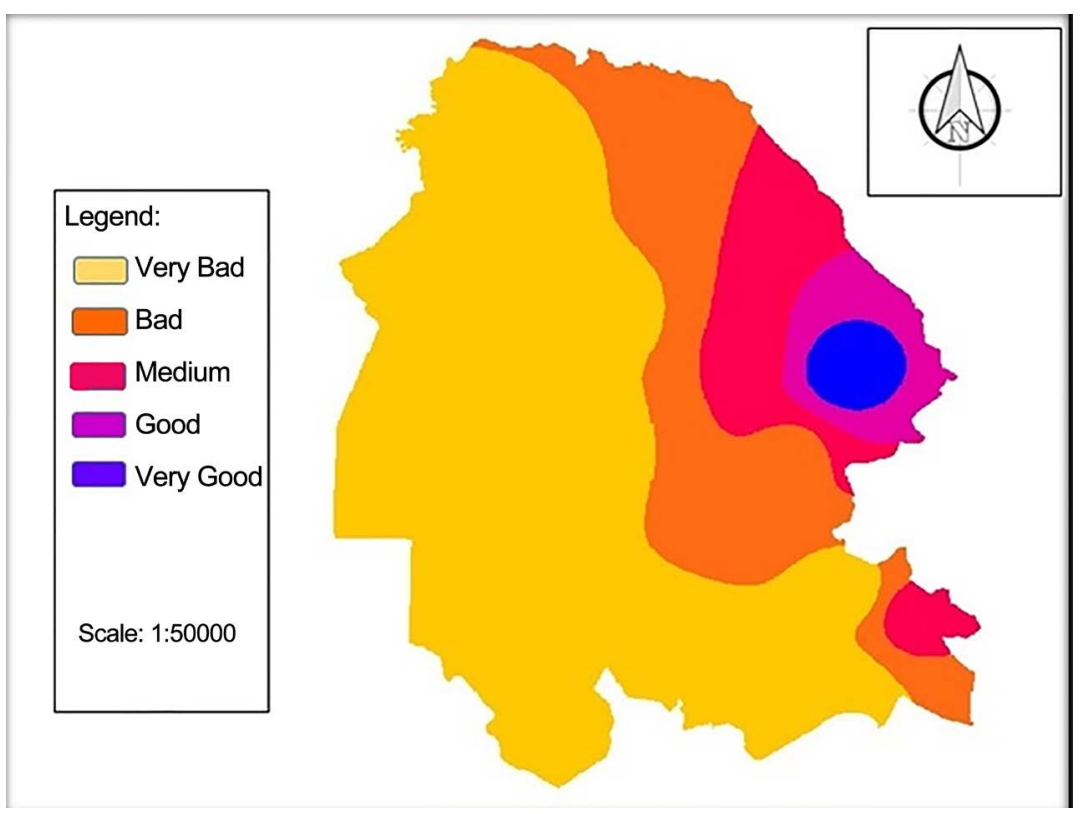

Figure 3. The status of land assessment in August, summer. 


\subsection{Autumn}

In autumn and November conditions changed such that in addition to areas of the east, in the southeast there are areas with very good value and the least valuable areas are located just in a part of southwest and center [18] (Figure 4).

\subsection{Winter}

This season also has the same conditions with the summer, so that very good areas are in the east, the south and the west, and northwest has an unfavorable situation in terms of environmental assessment. As the summer, we can observe modest circumstances in terms of climate elements in some part of the southeast areas [18] (Figure 5).

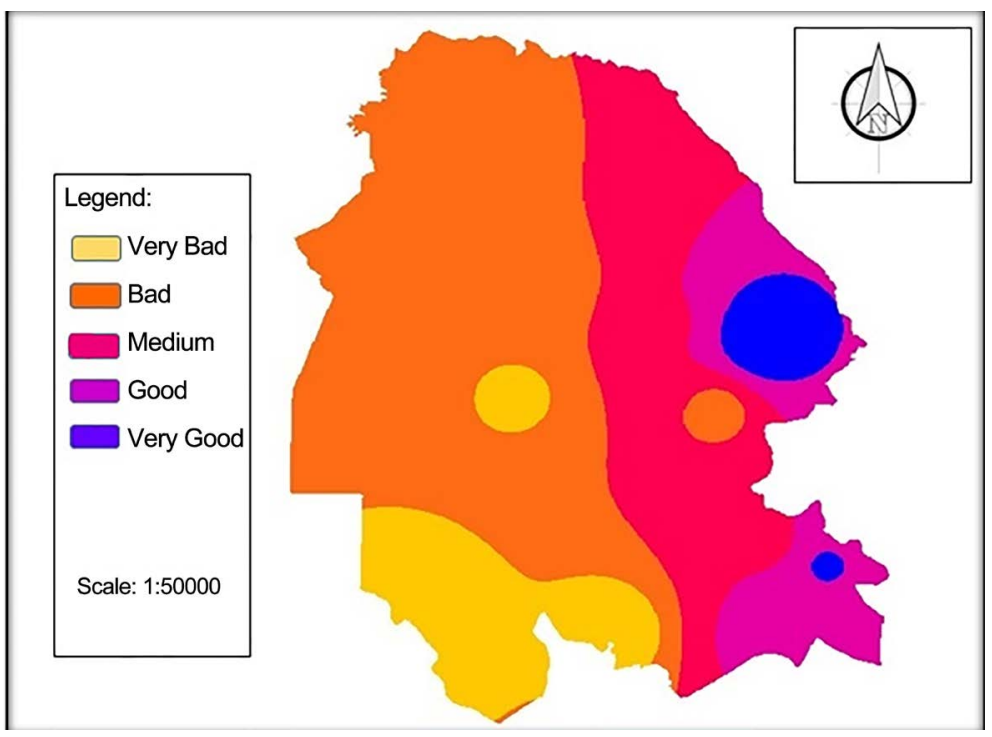

Figure 4. The status of land assessment in November, autumn.

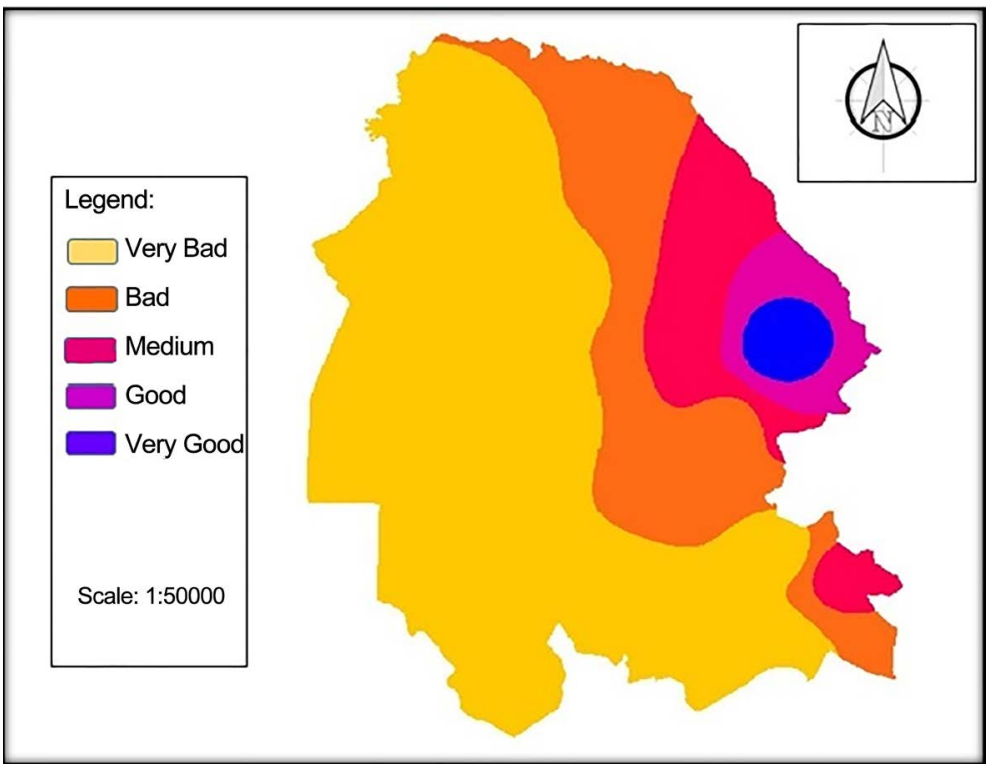

Figure 5. The status of land assessment in February, winter. 


\section{Conclusion}

Today, what has stated environmental assessment as a fundamental infrastructure for a variety of sciences is that as the environment science provides the context for any kinds of human activity and this is the biggest help to the human species for proper and useful use of their environment, but what can be concluded from the analysis is that in terms of climatic elements Khuzestan province is in poor conditions and the only part which in all seasons has the potential and the necessary conditions for agriculture is in the eastern parts of the province and sometimes in the southeast parts. Unfortunately, throughout the south, southwest and northwest are not in good conditions in terms of climatic elements and southwest areas are in more unfavorable conditions. It is suggested that in these areas where there are severe environmental situations, agricultural species should be used. Those species require little water and also are highly resistant to solar radiation and temperature. In the more favorable areas due to availability of conditions, species should be used that consume more water for agricultural purposes.

\section{References}

[1] Saeedi, A. (2004) Foundations of Rural Geography. SAMT Publication, Tehran, 162.

[2] Etedali, S. and Givi, J. (2012) Qualitative Land Suitability Assessment in Shahrekord for Corn Forage in FAO Method and Using the ALES Program. Journal of Soil and Water (Agricultural Science and Technology), 26, 1349-1359.

[3] Bameri, M., Bahrami, H.A. and Masih Abadi, M.H. (2003) Qualitative Land Suitability Evaluation for Irrigated Wheat, Barley and Alfalfa Cultivation in Chahshoor Plain, Iranshahr Region. Journal of Soil and Water Sciences, 17, 190-200.

[4] Mohammadi, J. and Giyoof, J. (2007) Land Suitability Assessment for Irrigated Wheat in Felavarjan Region (Isfahan) Using the Theory of Fuzzy Sets. Journal of Science and Technology of Agriculture and Natural Resources, 5, 103-116.

[5] FAO (1976) A Framework for Land Evaluation. FAO and Agriculture Organization, Rome.

[6] Maghami Moghim, F., Karimi, A.R., Hagh Niaf Gholam, H. and Door Andish, A. (2013) Determining Assessment Criteria to Identify Suitable Lands for Rain-Fed Crops in Roein Region (North Khorasan). Journal of Agricultural Ecology, 5, 143 152.

[7] Taleiee, M., Soleimani, H. and Faraj Zadeh Asl, M. (2014) Land Suitability Evaluation for Cultivation of Wheat, Based on the FAO Model and Fuzzy-AHP-OWA Technique in GIS Environment (Case Study: Miyaneh County). Journal of Soil and Water (Agricultural Science and Technology), 28, 139-156.

[8] Hossein Zadeh, M.M., Rostami, A. and Khodadadi, F. (2011) Determining the Ability of Fame in Lands for Agricultural and Pastures Use. Researches in Earth Sciences, 2, 43-57.

[9] Givi, J. (1997) Qualitative Evaluation of Land Suitability for Field and Fruit Crops. Iranian Soil and Water Research Institute, 1015, 23-72.

[10] Ghahroodi Tali, M. and Babaiee Fini, O. (2012) Introduction to Geographic Information Systems. Payam Noor University, Tehran, 4.

[11] Haywood, Y., Cornelius, S. and Karor, S. (2002) Introduction to Geographic Infor- 
mation Systems. Tajvidi, G., Trans., Iran Mapping Agency Publication, Tehran.

[12] Abidin, H.Z. (2007) Penentuam Posisi Dengom GPS dan aplikasinya. PT Pradnga Paramita, Jakarta.

[13] Indarto (2013) Analysis Geostatistik. Graha Ilma, Jakarta.

[14] Mitchell, A. (2005) The ESRI Guide to GIS Analysis, Volume 2: Spatial Measurement and Statistics. ESRI Press, California.

[15] Zanjirchi, M. (2011) Fuzzy Analytic Hierarchy Process. 11th Edition, Sanei Publication, Tehran.

[16] Buckley, J.J. (1985) Fuzzy Hierarchical. Journal of Fuzzy Sets and System, 32, 233-247. https://doi.org/10.1016/0165-0114(85)90090-9

[17] Nasri, R.M. (2012) Analysis keruangan kesesuaian lahan untuk permukiman di kabupatem bandung dan bandung barat. Forum Geografi, 26, 190-201.

[18] Meteorological Organization of Khuzestan Province (2016)

http://37.32.40.3/

Submit or recommend next manuscript to SCIRP and we will provide best service for you:

Accepting pre-submission inquiries through Email, Facebook, LinkedIn, Twitter, etc. A wide selection of journals (inclusive of 9 subjects, more than 200 journals)

Providing 24-hour high-quality service

User-friendly online submission system

Fair and swift peer-review system

Efficient typesetting and proofreading procedure

Display of the result of downloads and visits, as well as the number of cited articles

Maximum dissemination of your research work

Submit your manuscript at: http://papersubmission.scirp.org/

Or contact ojg@scirp.org 